\title{
Safety and efficacy of a fixed versus unfixed brinzolamide/timolol combination in Japanese patients with open-angle glaucoma or ocular hypertension
}

Mikio Nagayama'

Toru Nakajima ${ }^{2}$

Junji Ono ${ }^{3}$

'Nagayama Eye Clinic, Okayama, ${ }^{2}$ Nakajima Eye Clinic, Shizuoka, ${ }^{3}$ Ono Ophthalmic Clinic, Shizuoka, Japan
Correspondence: Mikio Nagayama Nagayama Eye Clinic, 3-2 Goban-cho, Kasaoka-shi, Okayama, Japan

Tel +8I 865623123

Fax +81865623122

Email nagayama-eye@po.harenet.ne.jp
This article was published in the following Dove Press journal:

Clinical Ophthalmology

13 January 2014

Number of times this article has been viewed

Background: The purpose of this study was to assess the safety and efficacy of fixed-combination brinzolamide $1 \% /$ timolol $0.5 \%$ (BRINZ/TIM-FC) compared with concomitant brinzolamide $1 \%$ and timolol $0.5 \%$ (BRINZ + TIM) in Japanese patients with open-angle glaucoma (primary open-angle, exfoliation, pigmentary) or ocular hypertension.

Methods: This randomized, double-masked, multicenter, parallel-group, positive-control, Phase III study was conducted in Japan and included patients aged $\geq 20$ years. Baseline intraocular pressure was assessed after 4 weeks of treatment with timolol $0.5 \%$. Patients were randomized to twice-daily BRINZ/TIM-FC or BRINZ + TIM for 8 weeks (treatment phase). The primary endpoint was mean intraocular pressure reduction from baseline to week 8 at $11 \mathrm{am}$, at which time noninferiority of BRINZ/TIM-FC versus BRINZ + TIM was evaluated. Data were analyzed using repeated-measures analysis of covariance and $t$-tests. Adverse events and ophthalmic/physiologic variables were assessed.

Results: In total, 319 patients of mean age $64 \pm 12$ years were enrolled in the treatment phase. BRINZ/TIM-FC and BRINZ + TIM were associated with reductions in mean intraocular pressure from baseline throughout the study (ranges -2.5 to $-3.4 \mathrm{mmHg}$ and -2.7 to $-3.3 \mathrm{mmHg}$, respectively). Mean between-group differences in intraocular pressure reduction ranged from 0 to $-0.3 \mathrm{mmHg}$; the upper limit of the $97.5 \%$ confidence interval for week 8 at 11 am was $<1.1 \mathrm{mmHg}$, indicating noninferiority of BRINZ/TIM-FC. Treatment-related adverse events were observed in $3 \%$ and $12 \%$ of patients receiving BRINZ/TIM-FC and BRINZ + TIM, respectively. No substantial changes in other safety parameters were reported.

Conclusion: Twice-daily BRINZ/TIM-FC reduced intraocular pressure by levels similar to concomitant BRINZ + TIM in Japanese patients with open-angle glaucoma or ocular hypertension and was noninferior to BRINZ + TIM. Both treatments were well tolerated.

Keywords: Azarga ${ }^{\circledR}$, open-angle glaucoma, intraocular pressure

\section{Introduction}

Glaucoma and ocular hypertension are progressive, vision-threatening conditions associated with increased intraocular pressure (IOP). Quigley and Broman have reported that, by 2020, more than 28 million people in Asia and nearly 60 million people worldwide will be diagnosed with open-angle glaucoma. ${ }^{1}$ In Japan, glaucoma is the leading cause of visual impairment. ${ }^{2}$ Reducing IOP is currently the only established treatment for slowing or preventing progression of open-angle glaucoma and ocular hypertension, ${ }^{3}$ which, if untreated, can lead to visual field defects and blindness. ${ }^{4}$ Multiple classes of IOP-lowering agents have been developed for therapeutic use, 
including carbonic anhydrase inhibitors and beta-adrenergic receptor antagonists ( $\beta$-blockers). ${ }^{3}$ Systemic administration of carbonic anhydrase inhibitors and $\beta$-blockers, among other agents, can produce adverse effects, including malaise, fatigue, and sleep disturbances; ${ }^{5,6}$ as a result, ophthalmic instillation has been pursued as a route of administration for treatment of glaucoma and ocular hypertension.

Many patients require multiple ocular hypotensive agents to achieve sufficient IOP reduction. ${ }^{7}$ Topical treatment with the nonselective $\beta$-blocker timolol $0.5 \%$ (TIM) and an adjunctive agent to lower IOP has become increasingly common., Concomitant therapy with topical brinzolamide 1\% (BRINZ), a carbonic anhydrase inhibitor, and TIM has been demonstrated to significantly decrease IOP in patients with glaucoma or ocular hypertension. ${ }^{9-11}$ Both BRINZ and TIM, individually and in combination, are generally well tolerated. ${ }^{10-14}$

Concomitant administration of multiple topical agents has been associated with drug washout, increased complexity of administration, and decreased treatment compliance; these factors can decrease delivery of effective doses of ocular hypotensives. ${ }^{15-17}$ Fixed-combination pharmacotherapies of IOP-lowering agents eliminate risk of washout and simplify drug administration. ${ }^{16,17}$ The safety and efficacy of fixed-combination brinzolamide 1\%/timolol 0.5\% (BRINZ/ TIM-FC) have been established in adult patients with glaucoma or ocular hypertension; because BRINZ/TIM-FC has been marketed in the European Union, earlier studies included mostly white or black patients and relatively few Asian patients. ${ }^{18-22}$ In a double-masked, parallel-group study, BRINZ/TIM-FC achieved significantly superior IOP reduction compared with BRINZ or TIM monotherapy. ${ }^{22}$ Furthermore, patients transitioned to BRINZ/TIM-FC (usually because of insufficient IOP reduction with or intolerance to their previous treatment) achieved significant IOP reductions from baseline after 4-6 weeks of therapy, and nearly $90 \%$ of patients judged the tolerability of BRINZ/TIM-FC positively. ${ }^{19}$

The objective of this randomized, double-masked, multicenter, parallel-group, controlled study was to evaluate the safety and efficacy of BRINZ/TIM-FC compared with concomitant therapy of unfixed BRINZ and TIM $(B R I N Z+T I M)$ in Japanese patients with open-angle glaucoma or ocular hypertension. The main hypothesis tested was that the IOP-lowering efficacy of BRINZ/TIM-FC is similar to that of BRINZ + TIM.

\section{Materials and methods Study design}

This was a Phase III, randomized, double-masked, multicenter, parallel-group, positive-controlled study (Figure 1) conducted at 34 sites in Japan. At the screening visit (week -4), patients gave their written informed consent to participate in the study and were evaluated for inclusion and exclusion criteria and use of prohibited or restricted concomitant drugs. Use of other IOP-lowering agents was suspended for the duration of the study. Patients were instructed to administer TIM twice daily at 9 am ( \pm 30 minutes) and 9 pm ( \pm 30 minutes $)$ until the baseline visit (observation phase). At the baseline visit (week 0), conducted $28 \pm 7$ days after screening, eligibility was confirmed based on inclusion and exclusion criteria and compliance with TIM therapy during the observation phase. Patients were randomized to BRINZ/TIM-FC or BRINZ + TIM treatment groups and instructed to instill the appropriate active agent(s) or placebo (ie, BRINZ/TIM-FC and matched placebo or BRINZ and TIM) twice daily, at 9 am

\section{BRINZ/TIM-FC}

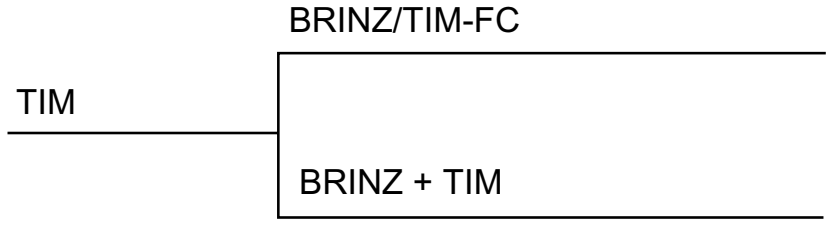

\begin{tabular}{|c|c|c|c|}
\hline $\begin{array}{l}\text { Observatior } \\
\text { phase, } 4 \text { we }\end{array}$ & $\begin{array}{l}\text { Dou } \\
\text { pha }\end{array}$ & $\begin{array}{l}\text {-masked treatment } \\
8 \text { weeks }\end{array}$ & \\
\hline Week -4 & Week 0 & Week 4 & Week 8 \\
\hline $\begin{array}{l}\text { Screening } \\
\text { IOP-lowering agents } \\
\text { discontinued }\end{array}$ & $\begin{array}{l}\text { Baseline } \\
\text { Randomization }\end{array}$ & $\begin{array}{l}\text { IOP assessment } \\
\text { Safety assessments }\end{array}$ & $\begin{array}{l}\text { IOP assessment } \\
\text { Primary efficacy: } \\
\text { IOP reduction at } 11 \text { am } \\
\text { Safety assessments }\end{array}$ \\
\hline
\end{tabular}

Figure I Study design. Patients receiving BRINZ/TIM-FC self-administered the study drug plus placebo.

Abbreviations: BRINZ + TIM, unfixed concomitant brinzolamide $1 \%$ and timolol 0.5\%; BRINZ/TIM-FC, brinzolamide I\%/timolol $0.5 \%$ fixed combination; IOP, intraocular pressure. 
( \pm 30 minutes) and $9 \mathrm{pm}( \pm 30$ minutes), for 8 weeks (treatment phase). Efficacy and safety endpoints were assessed at 9 am (before instillation of ophthalmic solutions) and 11 am ( 2 hours post instillation) at baseline, week 4 , and week 8 . A total of 24 sites also performed efficacy and safety assessments at 4 pm ( 7 hours post instillation).

The institutional review board of each participating institution reviewed and approved the study protocol, and the study was conducted according to the Declaration of Helsinki.

\section{Patients}

Study participants were Japanese patients aged $\geq 20$ years with a diagnosis of open-angle glaucoma (primary openangle glaucoma, exfoliation glaucoma, pigmentary glaucoma) or ocular hypertension for whom TIM monotherapy provided insufficient IOP reduction. Patients were eligible for participation if IOP in at least one eye was in the range of 18-36 mmHg at both 9 am and 11 am at the baseline visit (week 0 ), with neither eye $>36 \mathrm{mmHg}$. Key exclusion criteria included a history of chronic or recurrent severe ocular inflammatory disease, ocular trauma or intraocular surgery within 6 months or laser eye surgery within 3 months of screening, ocular infection or endophthalmitis, retinal disease, hypersensitivity to study drugs, or use of confounding ophthalmic or systemic drugs (unless on a stable dosage regimen with no new administration from screening to the end of the treatment phase). Additionally, patients with maximum corrected visual acuity $\leq 0.2$ (decimal acuity) or an anterior chamber angle grade $<2$ in either eye were excluded.

\section{Treatment}

During the observation phase (week -4 to week 0 ), all patients instilled one drop of TIM aqueous ophthalmic solution in each eye twice daily. Throughout the treatment phase (week 0 to week 8), patients instilled either a placebo (an aqueous ophthalmic solution containing no active ingredient) followed by BRINZ/TIM-FC ophthalmic suspension (Azarga ${ }^{\circledR}$; Alcon Laboratories, Inc, Fort Worth, TX, USA) or TIM followed by BRINZ ophthalmic suspension (Alcon Laboratories, Inc), with concomitant instillations $\geq 5 \mathrm{~min}$ utes apart twice daily. At the screening visit, patients were provided with a journal and requested to record the conditions of investigational drug instillation and any changes in concomitant drugs.

\section{Efficacy assessments}

The primary efficacy endpoint was mean IOP change from baseline at 11 am ( 2 hours post instillation) at the week 8 visit.
Similarity of the IOP-lowering efficacy of BRINZ/TIM-FC versus BRINZ + TIM was evaluated (margin of noninferiority, $+1.1 \mathrm{mmHg}$ ). Secondary efficacy endpoints included mean IOP over time. IOP was measured by Goldmann applanation tonometry at screening and at $9 \mathrm{am}, 11 \mathrm{am}$, and 4 pm at baseline, week 4 , and week 8 .

\section{Safety assessments}

Adverse events were assessed at the baseline, week 4, and week 8 visits. Solicited and unsolicited adverse events were recorded at each visit and coded using the Medical Dictionary for Regulatory Activities Japanese translation, version 14.1. The following safety parameters were assessed at screening, baseline, week 4, and week 8: best corrected visual acuity (decimal acuity scale), slit lamp examination (cornea, eyelid/conjunctiva, iris/anterior chamber, lens), blood pressure, and pulse rate. Funduscopy (vitreous, retina/ macula/choroid, optic nerve, optic nerve cup-to-disc ratio), gonioscopy (anterior chamber angle grade), static perimetry (visual field stage, defined using Greve's modification of the Aulhorn classification ${ }^{23}$ ), and laboratory tests (hematology, serum chemistry, and qualitative urinalysis) were performed at screening and week 8 .

\section{Statistical analyses}

Mean changes in IOP from baseline for each group and the difference between groups were estimated with $95 \%$ confidence intervals (CIs) by a repeated-measures analysis of covariance model with baseline IOP values used as the covariate. Significance of the primary endpoint, ie, IOP reduction from baseline at the 11 am week 8 assessment, was determined by paired $t$-tests. Descriptive statistics were obtained for mean \pm standard deviation IOP and IOP change from baseline throughout the study. Noninferiority of BRINZ/TIM-FC versus BRINZ + TIM was considered to be proven if the upper limit of the one-sided 97.5\% CI of the difference between treatment groups in mean IOP change from baseline at $11 \mathrm{am}$ at week 8 was $<1.1 \mathrm{mmHg}$. Post hoc analyses of treatment group differences in incidence of adverse events were performed using Fisher's Exact tests.

Group sizes and statistical power were determined before initiation of the study. Assuming a standard deviation of $3.0 \mathrm{mmHg}$ for the IOP change from baseline, sample sizes of $\geq 135$ patients per group were determined to be sufficient to detect a difference in IOP $\geq 1.1 \mathrm{mmHg}$ within the coverage probability of the $97.5 \%$ upper CI with $85 \%$ power.

Efficacy was analyzed in the per-protocol population (defined as all patients who received study medication 
in the treatment phase, had post-administration tests and observation data, and satisfied the protocol criteria) and the intent-to-treat population (defined as all patients who received study medication in the treatment phase and who had post-administration tests and observation data). Safety variables were analyzed in the safety population (defined as all patients who received study medication).

\section{Results}

\section{Patients}

A total of 366 patients were enrolled in the observation phase. Of these, 319 continued into the treatment phase (BRINZ/TIM-FC, $\mathrm{n}=158$; BRINZ + TIM, $\mathrm{n}=161$; mean age $64 \pm 12$ years) and were included in the intent-to-treat data set (ie, all patients administered an investigational drug for whom post-administration tests and observation data existed). A total of 309 completed the study and were included in the per-protocol population. Forty-seven patients discontinued the study during the observation phase; the most frequent reasons for discontinuation from the observation phase were selection criteria $(n=25)$, meeting exclusion criteria $(n=10)$, and adverse events $(n=8)$. Ten patients discontinued the study during the treatment phase (Figure 2). Eleven cases of noncompliance occurred, five of which resulted in discontinuation.
Baseline demographic and diagnosis information for the per-protocol population are presented in Table 1. The treatment groups were balanced with regard to age, sex, and diagnosis. The majority of patients $(56 \%)$ were diagnosed with primary open-angle glaucoma, followed by ocular hypertension (41\%). No patients were diagnosed with normal-tension glaucoma.

\section{Efficacy}

Efficacy for the per-protocol and intent-to-treat populations was similar throughout the study; therefore, the efficacy data presented here are only from the per-protocol data set. Mean baseline IOP values were similar between the BRINZ/TIM-FC and BRINZ + TIM treatment groups at $9 \mathrm{am} \mathrm{(21.2} \mathrm{mmHg}$ and $21.0 \mathrm{mmHg}$, respectively), $11 \mathrm{am}$ (20.8 mmHg and $20.8 \mathrm{mmHg}$ ), and $4 \mathrm{pm} \mathrm{(19.8} \mathrm{mmHg} \mathrm{and}$ $20.3 \mathrm{mmHg}$ ). Mean IOP reductions from baseline with BRINZ/TIM-FC and BRINZ + TIM ranged from $-2.5 \mathrm{mmHg}$ to $-3.4 \mathrm{mmHg}$ and from $-2.7 \mathrm{mmHg}$ to $-3.3 \mathrm{mmHg}$, respectively, and were similar in the BRINZ/TIM-FC and BRINZ + TIM groups at all time points (Figure 3). Treatment comparisons of IOP values for patients who had assessments at two time points (ie, 9 am and $11 \mathrm{am}$ ) and those who had assessments at three time points (ie, 9 am, 11 am, and 4 pm)

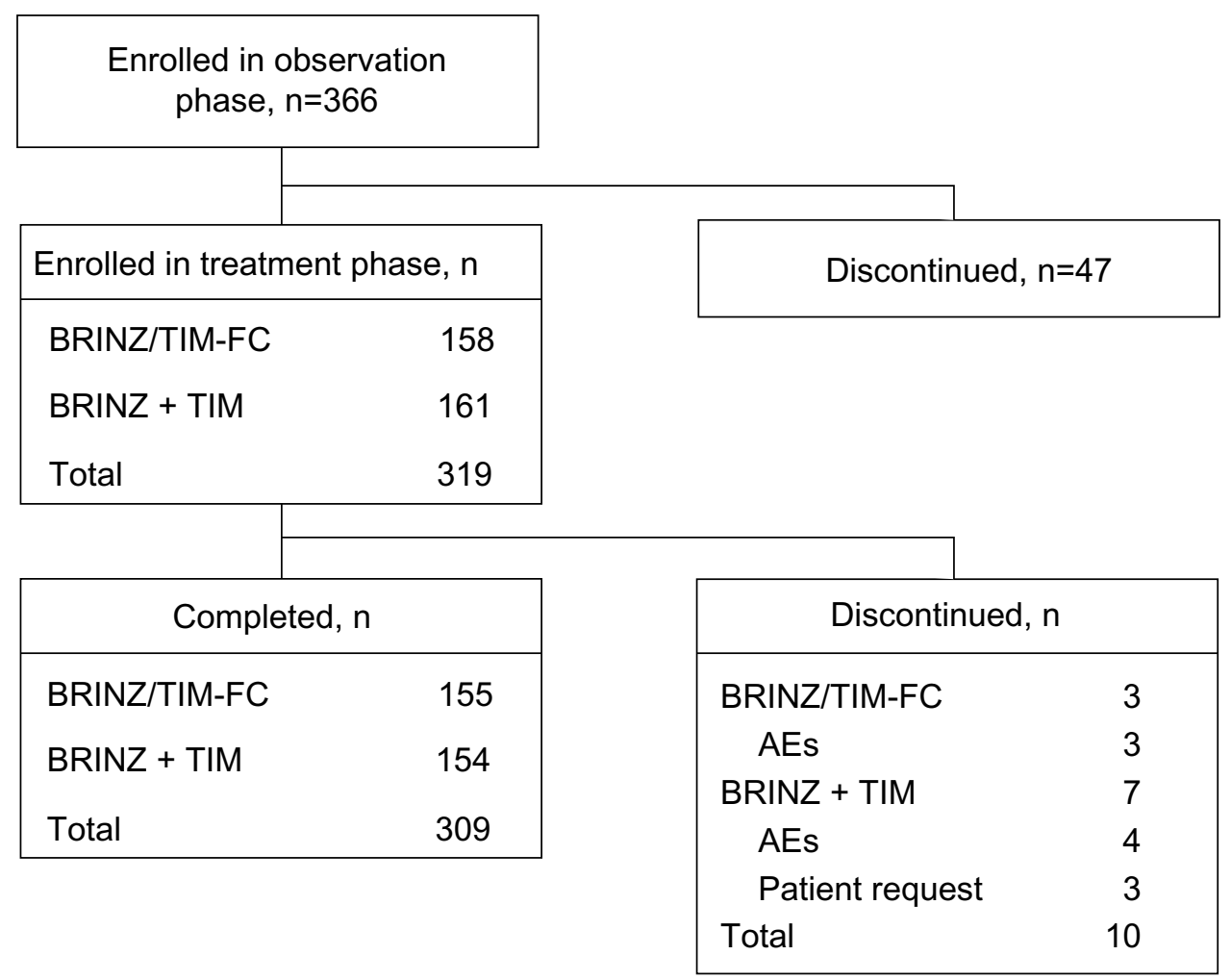

Figure 2 Patient disposition. Intent-to-treat population, $\mathrm{n}=3$ I8; per-protocol population, $\mathrm{n}=309$. 
Table I Patient demographics and diagnoses (per-protocol)

\begin{tabular}{|c|c|c|c|}
\hline & $\begin{array}{l}\text { BRINZ/TIM- } \\
\text { FC }(n=155)\end{array}$ & $\begin{array}{l}\text { BRINZ + } \\
\text { TIM }(n=154)\end{array}$ & $\begin{array}{l}\text { All patients } \\
(n=309)\end{array}$ \\
\hline \multicolumn{4}{|l|}{ Sex, n (\%) } \\
\hline Male & $76(49)$ & $78(5 \mathrm{I})$ & $154(50)$ \\
\hline Female & $79(51)$ & $76(49)$ & $155(50)$ \\
\hline $\begin{array}{l}\text { Mean } \pm \text { SD } \\
\text { age, years }\end{array}$ & $62 \pm 12$ & $65 \pm 11$ & $64 \pm 12$ \\
\hline \multicolumn{4}{|c|}{$\begin{array}{l}\text { age, years } \\
\text { Age group, years, n (\%) }\end{array}$} \\
\hline$<65$ & $79(5 \mathrm{I})$ & $61(40)$ & $140(45)$ \\
\hline$\geq 65$ & $76(49)$ & $93(60)$ & $169(55)$ \\
\hline 65 to $<75$ & $59(38)$ & $63(4 I)$ & 122 (39) \\
\hline 75 to $<85$ & $15(10)$ & $28(18)$ & $43(14)$ \\
\hline 85 to $<95$ & $2(1)$ & $2(1)$ & $4(I)$ \\
\hline \multicolumn{4}{|l|}{ Diagnosis, n (\%) } \\
\hline $\begin{array}{l}\text { Primary open- } \\
\text { angle glaucoma }\end{array}$ & $87(56)$ & $87(56)$ & $174(56)$ \\
\hline $\begin{array}{l}\text { Normal-tension } \\
\text { glaucoma }\end{array}$ & 0 & 0 & 0 \\
\hline $\begin{array}{l}\text { Exfoliation } \\
\text { glaucoma }\end{array}$ & $3(2)$ & $5(3)$ & $8(3)$ \\
\hline $\begin{array}{l}\text { Pigmentary } \\
\text { glaucoma }\end{array}$ & 0 & I (I) & I (0.3) \\
\hline $\begin{array}{l}\text { Ocular } \\
\text { hypertension }\end{array}$ & $65(42)$ & $61(40)$ & $126(4 \mid)$ \\
\hline
\end{tabular}

Abbreviations: BRINZ + TIM, unfixed concomitant brinzolamide $1 \%$ and timolol $0.5 \%$; BRINZ/TIM-FC, brinzolamide I\%/timolol $0.5 \%$ fixed combination; SD, standard deviation.

are presented in Tables 2 and 3, respectively. Reductions in IOP from baseline at the 11 am week 8 assessment (the primary efficacy endpoint) were significant in both the BRINZ/ TIM-FC and BRINZ + TIM treatment groups (least squares mean IOP reduction: BRINZ/TIM-FC, $-3.4 \mathrm{mmHg}, \mathrm{n}=150$;
BRINZ + TIM, $-3.3 \mathrm{mmHg}, \mathrm{n}=149$; both $P<0.0001$ ). The difference in least squares mean IOP reduction from baseline between treatments (BRINZ/TIM-FC minus BRINZ + TIM) ranged from $0.0 \mathrm{mmHg}$ to $-0.3 \mathrm{mmHg}$, and the upper limit of the $97.5 \%$ one-sided CI of the difference between groups at $11 \mathrm{am}$ in week 8 was $0.4 \mathrm{mmHg}$, which was within the margin of noninferiority of $<1.1 \mathrm{mmHg}$. During the treatment phase, descriptive statistics for mean IOP values were similar for BRINZ/TIM-FC and BRINZ + TIM (range 17.1-18.3 mmHg and 17.5-18.2 $\mathrm{mmHg}$, respectively; Figure 4).

No differing trends in IOP-lowering efficacy of BRINZ/ TIM-FC or BRINZ + TIM were found in patients diagnosed with primary open-angle glaucoma versus ocular hypertension. Mean IOP at baseline was similar between patient subgroups (primary open-angle glaucoma, 20.5-21.0 $\mathrm{mmHg}$; ocular hypertension, 20.4-21.3 $\mathrm{mmHg}$ ). Mean IOP reductions from baseline with BRINZ/TIM-FC were $-2.9 \mathrm{mmHg}$ to $-3.6 \mathrm{mmHg}$ and $-2.0 \mathrm{mmHg}$ to $-3.0 \mathrm{mmHg}$ in patients with primary open-angle glaucoma and ocular hypertension, respectively; IOP reductions with BRINZ + TIM were $-2.7 \mathrm{mmHg}$ to $-3.7 \mathrm{mmHg}$ and $-2.3 \mathrm{mmHg}$ to $-2.8 \mathrm{mmHg}$.

\section{Safety}

In total, 318 patients received an investigational drug during the treatment phase (safety population; BRINZ/TIM-FC, $\mathrm{n}=157$; BRINZ + TIM, $\mathrm{n}=161$ ). One or more adverse events were observed in $21 \%(n=68 / 318)$ of patients (BRINZ/ TIM-FC, n=29/157 [18\%]; BRINZ + TIM, n=39/161 [24\%]; $P=0.22$; Table 4). Most adverse events were mild or moderate;

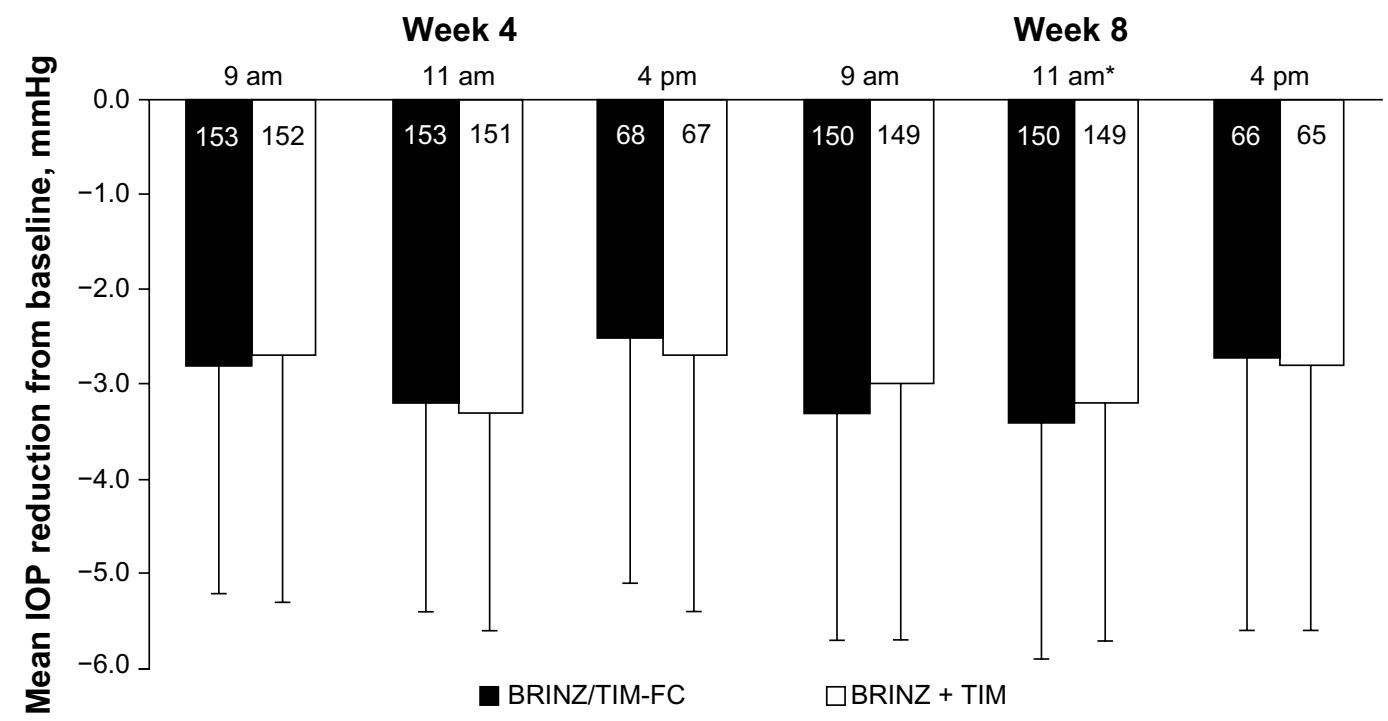

Figure 3 Mean \pm standard deviation IOP reduction from baseline with BRINZ/TIM-FC and BRINZ + TIM at 9 am (preinstillation), II am ( 2 hours post instillation), and 4 pm (7 hours post instillation). Group sizes are indicated in the bars. *Primary efficacy endpoint was evaluated at II am during the week 8 visit.

Abbreviations: BRINZ + TIM, unfixed concomitant brinzolamide I\% and timolol 0.5\%; BRINZ/TIM-FC, brinzolamide $1 \% /$ timolol $0.5 \%$ fixed combination; IOP, intraocular pressure. 
Table 2 Intraocular pressure for patients who had assessments at two time points (per-protocol population)*,†

\begin{tabular}{|c|c|c|c|c|c|c|}
\hline & \multicolumn{2}{|l|}{ Baseline } & \multicolumn{2}{|l|}{ Week 4} & \multicolumn{2}{|l|}{ Week 8} \\
\hline & 9 am & II am & 9 am & II am & 9 am & II am \\
\hline BRINZ/TIM-FC, LS mean (n) & $21.2(155)$ & $20.8(155)$ & $18.1(153)$ & $17.6(153)$ & $17.7(150)$ & $17.5(150)$ \\
\hline BRINZ + TIM, LS mean (n) & $21.0(154)$ & $20.8(154)$ & $18.2(152)$ & $17.6(|5|)$ & $18.0(149)$ & $17.6(149)$ \\
\hline Treatment group difference & 0.2 & 0.1 & -0.1 & 0.0 & -0.3 & -0.1 \\
\hline$P$-value & 0.4966 & 0.8488 & 0.8383 & 0.8647 & 0.3303 & 0.6569 \\
\hline $95 \% \mathrm{Cl}$ & -0.4 to 0.8 & -0.5 to 0.7 & -0.6 to 0.5 & -0.5 to 0.6 & -0.8 to 0.3 & -0.7 to 0.4 \\
\hline
\end{tabular}

Notes: *All data are $\mathrm{mmHg}$; ${ }^{\dagger}$ estimates based on LS mean using repeated-measures analysis of covariance adjusted with baseline IOP; ${ }^{\ddagger}$ primary endpoint.

Abbreviations: BRINZ + TIM, unfixed concomitant brinzolamide I\% and timolol $0.5 \%$; BRINZ/TIM-FC, brinzolamide $1 \% /$ timolol $0.5 \%$ fixed combination; Cl, confidence interval; IOP, intraocular pressure; LS, least squares.

one serious adverse event, ie, coronary spastic angina, for which a causal relationship with treatment could not be ruled out, occurred in a patient in the BRINZ + TIM group. A post hoc analysis showed that significantly fewer treatment-related adverse events occurred in BRINZ/TIM-FC-treated patients (3\%) compared with BRINZ + TIM-treated patients (12\%; $P=0.0029$; Table 4$)$. The most frequently reported treatmentrelated adverse events were blurred vision and eye irritation (Table 4). The most common treatment-emergent adverse event (observed in $\geq 2 \%$ of patients) with BRINZ/TIM-FC was nasopharyngitis $(\mathrm{n}=6 / 157$ [4\%]); with BRINZ + TIM, the most common treatment-emergent adverse events were blurred vision $(n=5 / 161[3 \%])$, eye irritation $(n=4 / 161[2 \%])$, and allergic conjunctivitis ( $\mathrm{n}=4 / 161[2 \%])$.

Additional visual and ophthalmic safety parameters, including best corrected visual acuity, visual field, optic nerve cup-to-disc ratio, angle grade, and intraocular and external features assessed by slit-lamp and funduscopy were largely unchanged from baseline to week 8 . Deterioration in visual field score from baseline was observed in $3 \%(n=5 / 156)$ of patients who received BRINZ/TIM-FC and 7\% $(n=11 / 161)$ of patients who received BRINZ + TIM.

There were no substantial variations in hematology, serum chemistry, or urinalysis parameters in either treatment group over time. Many changes in laboratory measurements were within the range of physiologic variation. Further, no substantial variations in blood pressure or pulse rate were observed.

\section{Discussion}

The primary treatment approach for glaucoma and ocular hypertension is to reduce IOP and prevent disease progression. ${ }^{3,7}$ Clinical studies have demonstrated that multiple hypotensive agents are often required to achieve sufficient IOP reduction. ${ }^{7,24}$ Increasing use of multiple antiglaucoma medications over time was previously observed in Japanese patients. ${ }^{25}$ Fixed-combination pharmacotherapies of multiple ocular hypotensive agents, including BRINZ/ TIM-FC, were shown to reduce IOP in patients with glaucoma and ocular hypertension, with greater efficacy than their component monotherapies..$^{22,26-28}$ Furthermore, compared with unfixed combination therapies (ie, multiple medication bottles), fixed-combination therapies can decrease cumulative patient exposure to preservatives, reduce risk of drug washout, and simplify drug administration. ${ }^{15-17,29}$

The goal of the current study was to evaluate the safety and efficacy of BRINZ/TIM-FC compared with unfixed concomitant BRINZ + TIM in Japanese patients with

Table 3 Intraocular pressure for patients who had assessments at three time points (per-protocol population)*,t

\begin{tabular}{|c|c|c|c|c|c|c|c|c|c|}
\hline & \multicolumn{3}{|l|}{ Baseline } & \multicolumn{3}{|l|}{ Week 4} & \multicolumn{3}{|l|}{ Week 8} \\
\hline & 9 am & II am & 4 pm & $9 \mathrm{am}$ & II am & $4 \mathrm{pm}$ & 9 am & II am & $4 \mathrm{pm}$ \\
\hline $\begin{array}{l}\text { BRINZ/TIM-FC, } \\
\text { LS mean (n) }\end{array}$ & $21.3(69)$ & $21.2(69)$ & $19.8(69)$ & $18.0(68)$ & $17.6(68)$ & $17.6(68)$ & $17.6(67)$ & I7.3 (67) & I7.4 (66) \\
\hline $\begin{array}{l}\text { BRINZ + TIM, } \\
\text { LS mean }(n)\end{array}$ & $20.9(70)$ & $20.8(70)$ & $20.3(70)$ & I8.2 (69) & I7.8 (69) & I 7.7 (67) & I8.0 (67) & I7.6 (67) & $17.6(65)$ \\
\hline $\begin{array}{l}\text { Treatment group } \\
\text { difference }\end{array}$ & 0.4 & 0.4 & -0.5 & -0.2 & -0.2 & -0.1 & -0.5 & -0.3 & -0.2 \\
\hline$P$-value & 0.4180 & 0.4199 & 0.3272 & 0.6692 & 0.6598 & 0.7785 & 0.2743 & 0.5398 & 0.6921 \\
\hline $95 \% \mathrm{Cl}$ & -0.6 to 1.4 & -0.6 to 1.4 & -1.5 to 0.5 & -1.1 to 0.7 & -1.1 to 0.7 & -1.0 to 0.7 & -1.4 to 0.4 & -1.1 to 0.6 & -1.1 to 0.7 \\
\hline
\end{tabular}

Notes: *All data are $\mathrm{mmHg}$; ${ }^{\dagger}$ estimates based on LS mean using repeated-measures analysis of covariance adjusted with baseline IOP.

Abbreviations: BRINZ + TIM, unfixed concomitant brinzolamide I\% and timolol $0.5 \%$; BRINZ/TIM-FC, brinzolamide $1 \% /$ timolol $0.5 \%$ fixed combination; Cl, confidence interval; IOP, intraocular pressure; LS, least squares. 


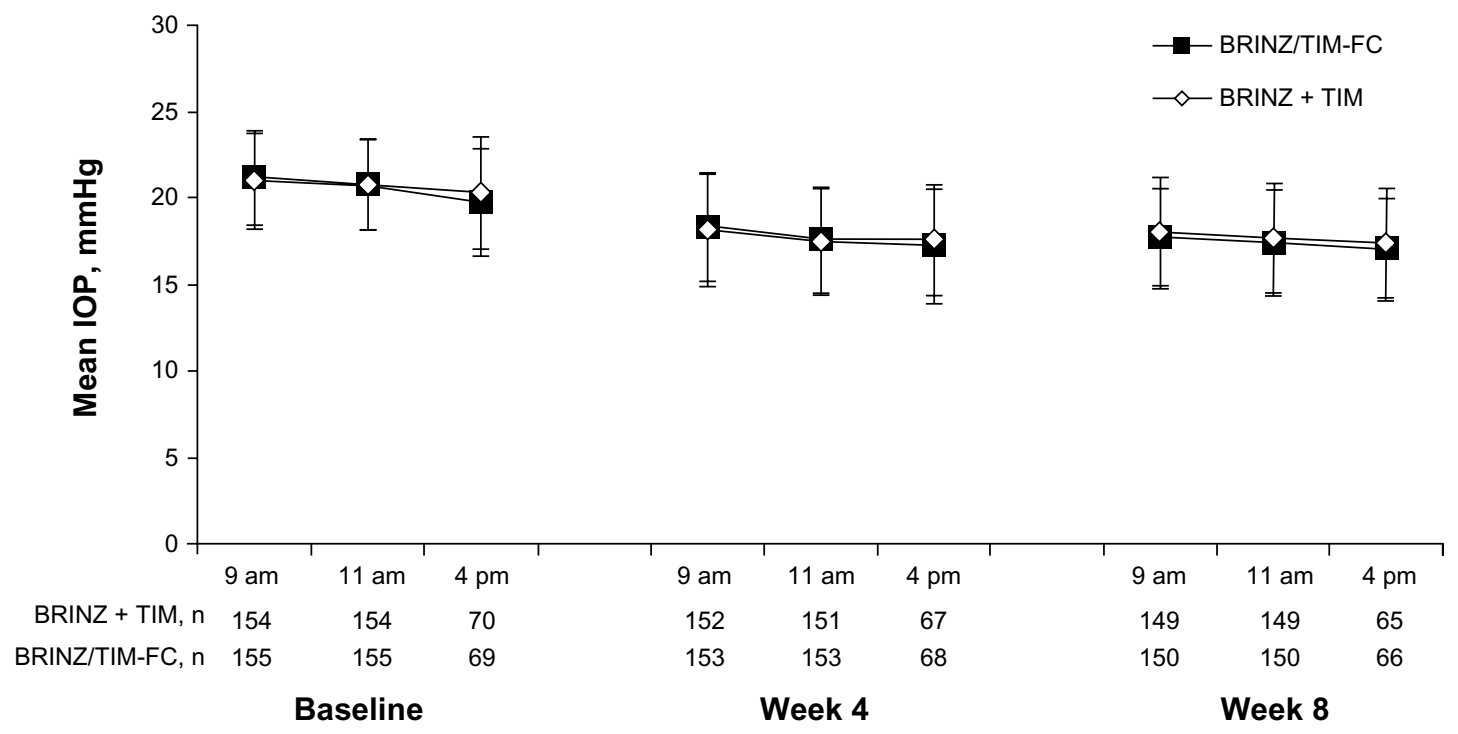

Figure 4 Mean \pm standard deviation IOP over time from baseline through week 8 at 9 am (preinstillation), II am ( 2 hours post instillation), and 4 pm ( 7 hours post instillation). Abbreviations: BRINZ + TIM, unfixed concomitant brinzolamide $1 \%$ and timolol $0.5 \%$; BRINZ/TIM-FC, brinzolamide $1 \% /$ timolol $0.5 \%$ fixed combination; IOP, intraocular pressure.

open-angle glaucoma (primary open-angle, exfoliation, pigmentary) or ocular hypertension. Both BRINZ/TIM-FC and BRINZ + TIM produced significant IOP reductions from baseline over 8 weeks of treatment; IOP reductions with BRINZ/TIM-FC were numerically equal to or greater than those with BRINZ + TIM at all time points. The IOPlowering efficacy of BRINZ/TIM-FC and BRINZ + TIM was similar in patients diagnosed with primary open-angle glaucoma versus ocular hypertension. Adverse events occurring with BRINZ/TIM-FC and BRINZ + TIM were mostly of mild or moderate severity, and post hoc analysis suggested that fewer treatment-related adverse events occurred with BRINZ/TIM-FC compared with BRINZ + TIM. No substantial or clinically relevant aggravations of visual and ophthalmic safety parameters of disease progression were observed with either treatment.

The safety and efficacy of BRINZ/TIM-FC and BRINZ + TIM in this study were consistent with those reported in previous studies of these agents as combination therapy and monotherapy in other patient populations. ${ }^{10,11,18,19,21,22,30,31}$ Similar to the current study, which demonstrated comparable efficacy of BRINZ/TIM-FC and unfixed concomitant BRINZ + TIM, other clinical assessments of fixed-combination therapies have demonstrated that fixed-combination pharmacotherapies containing TIM and dorzolamide, a carbonic anhydrase inhibitor, or latanoprost, a prostaglandin analog, have efficacy similar to that of concomitant treatment with their active components. ${ }^{32-35}$ Fixed-combination dorzolamide 1\%/TIM is approved for use in Japan; there are currently no comparative data for BRINZ/TIM-FC versus the fixed combination of dorzolamide 1\%/TIM. However, in a previous multinational noninferiority study conducted in Europe, BRINZ/TIM-FC produced IOP reductions similar to those achieved with fixed-combination dorzolamide 2\%/TIM. ${ }^{20}$ Further, studies conducted in the US and South America indicate that among patients with a treatment preference, BRINZ/TIM-FC was favored by patients over fixed-combination dorzolamide $2 \% /$ TIM. ${ }^{21,31}$ This result may be attributable to the increased severity and duration of ocular discomfort with dorzolamide 2\%/ TIM compared with BRINZ/TIM-FC. . $82,31,36$ Patients in the current study reported a low incidence of dysgeusia, a result that may be related to adequate informed consent (including explanation of adverse events) before study participation.

Based on the similar IOP-lowering efficacy of BRINZ/ TIM-FC and BRINZ + TIM, BRINZ/TIM-FC is expected to provide a benefit to patients with glaucoma as a substitute for unfixed concomitant BRINZ + TIM in terms of both treatment convenience and compliance. Additional studies are needed to confirm this hypothesis. A potential limitation of the current study is that the study population did not include any patients with normal-tension or closed-angle glaucoma; both of these conditions are common in people of Japanese descent. ${ }^{1,37}$ Additionally, future studies of patients with pigmentary or exfoliation open-angle glaucoma are needed; because of the small numbers of patients with these glaucoma etiologies in the current study, conclusions regarding the safety and efficacy of BRINZ/TIM-FC in these patients should be made with caution. 
Table 4 Adverse events (safety population)

\begin{tabular}{|c|c|c|}
\hline & $\begin{array}{l}\text { BRINZ/TIM-FC } \\
(n=I 57)\end{array}$ & $\begin{array}{l}\text { BRINZ + TIM } \\
(n=161)\end{array}$ \\
\hline Total AEs, n (\%) & $29(18)$ & $39(24)$ \\
\hline \multicolumn{3}{|l|}{ Age, $n / N(\%)$} \\
\hline$<65$ years & $|6 / 8|(20)$ & $19 / 65(29)$ \\
\hline$\geq 65$ years & $13 / 76(17)$ & $20 / 96(21)$ \\
\hline \multicolumn{3}{|l|}{ Sex, n/N (\%) } \\
\hline Male & $16 / 78(21)$ & $15 / 82(18)$ \\
\hline Female & $13 / 79(16)$ & $24 / 79(30)$ \\
\hline \multicolumn{3}{|c|}{$\mathrm{AE}$ severity, $\mathrm{n}$ (treatment related/total) } \\
\hline Mild & $5 / 22$ & $17 / 33$ \\
\hline Moderate & $0 / 7$ & $3 / 9$ \\
\hline Severe & $0 / 0$ & $1 / 1$ \\
\hline Treatment-related AEs,* n (\%) & $5(3)$ & $20(12)$ \\
\hline Punctate keratitis & $\mathrm{I}(\mathrm{I})$ & $2(I)$ \\
\hline Blurred vision & $\mathrm{I}(\mathrm{I})$ & $5(3)$ \\
\hline Eye irritation & $\mathrm{I}(\mathrm{I})$ & $4(2)$ \\
\hline Eye pruritus & $\mathrm{I}(\mathrm{I})$ & $I(I)$ \\
\hline Dysgeusia & $\mathrm{I}(\mathrm{I})$ & 0 \\
\hline Allergic conjunctivitis & 0 & $\mathrm{I}(\mathrm{I})$ \\
\hline Eye pain & 0 & $I(I)$ \\
\hline Ocular hyperemia & 0 & $2(1)$ \\
\hline Eye discharge & 0 & $\mathrm{I}(\mathrm{I})$ \\
\hline Keratitis & 0 & $\mathrm{I}(\mathrm{I})$ \\
\hline Coronary spastic angina & 0 & $\mathrm{I}(\mathrm{I})$ \\
\hline Cough & 0 & $\mathrm{I}(\mathrm{I})$ \\
\hline Nasal congestion & 0 & $I(I)$ \\
\hline Vomiting & 0 & $\mathrm{I}(\mathrm{I})$ \\
\hline $\begin{array}{l}\text { Alanine aminotransferase } \\
\text { increased }\end{array}$ & 0 & I (I) \\
\hline $\begin{array}{l}\text { Aspartate aminotransferase } \\
\text { increased }\end{array}$ & 0 & $I(I)$ \\
\hline $\begin{array}{l}\text { Blood alkaline phosphatase } \\
\text { increased }\end{array}$ & 0 & $I(I)$ \\
\hline Renal function test abnormal & 0 & $\mathrm{I}(\mathrm{I})$ \\
\hline
\end{tabular}

Note: $* P=0.0029$ for BRINZ/TIM-FC versus BRINZ + TIM.

Abbreviations: AE, adverse event; BRINZ + TIM, unfixed concomitant brinzolamide $1 \%$ and timolol $0.5 \%$; BRINZ/TIM-FC, brinzolamide $1 \% /$ timolol $0.5 \%$ fixed combination.

\section{Conclusion}

Treatment with twice-daily BRINZ/TIM-FC significantly reduced IOP throughout this 8 -week study in Japanese patients with open-angle glaucoma or ocular hypertension. IOP-lowering efficacy was similar with BRINZ/TIM-FC and BRINZ + TIM. Further, the safety profiles of BRINZ/ TIM-FC and BRINZ + TIM were similar, and both therapies were well tolerated.

\section{Acknowledgments}

The authors thank the following participating investigators: Koji Aoyagi (Aoyagi Eye Clinic), Shinshi Chin (Asahigaoka Eye Clinic), Seiichiro Fujii (Nishi Eye Hospital), Takashi Godo (Godo Eye Clinic), Reiko Ishida (Ishida Eye Clinic),
Ryuzo Itabashi (Itabashi Eye Hospital), Mutsuko Ito (Ito Eye Clinic), Kazunori Kamio (Kamio Eye Clinic), Atsuko Kitigawa (Kitigawa Eye Clinic), Sachi Kobayashi (Amaki Clinic), Tomoaki Koike (Ageo Central General Hospital), Daisaku Kudo (Nishio Municipal Hospital), Yoshinori Kurata (Kurata Eye Clinic), Jun Matsumoto (Keio Hachioji Matsumoto Eye Clinic), Masako Matsuura (Matsuura Eye Clinic), Kiichiro Mitani (Mitani Eye Clinic), Hideaki Mizote (Mizote Eye Clinic), Yuichiro Nakanishi (Kikugawa Eye Clinic), Sumiyo Noge (Murakami Karindo Hospital), Ryoji Nomura (Nomura Eye Clinic), Tomohito Nonoyama (Nonoyama Eye Clinic), Takashi Okano (Smile Eye Clinic), Tamotsu Seki (Tamagawa Eye Clinic), Yuko Shibuya (Shibuya Eye Clinic), Hideyo Shin (Oguchi Ophthalmic Clinic), Makoto Shirao (Shirao Eye Clinic), Kenichi Takahashi (Takahashi Eye Clinic), Kazuo Tsuji (Tsuji Eye Clinic), Hiroki Watanabe (Watanabe Eye Clinic), Koji Yamada (Yamada Ophthalmic Clinic), and Satoshi Yamaguchi (Yamaguchi Ophthalmic Clinic).

\section{Author contributions}

All authors contributed to the study and to the manuscript preparation. The manuscript was written with the collaboration of Alcon and was reviewed and approved by the authors.

\section{Disclosure}

This study was funded by Alcon Japan Ltd (Tokyo, Japan). Alcon designed and conducted the study and undertook the data collection, management, and analysis of data. $\mathrm{MN}$ was compensated by Alcon Japan Ltd for his work drafting and reviewing the manuscript, but has no other financial interests to disclose. TN and JO have no financial interests to disclose. Medical writing assistance was provided by Heather Starkey of Complete Healthcare Communications, Inc. (Chadds Ford, PA, USA), and was funded by Alcon.

\section{References}

1. Quigley HA, Broman AT. The number of people with glaucoma worldwide in 2010 and 2020. Br J Ophthalmol. 2006;90(3):262-267.

2. Yamada M, Hiratsuka Y, Roberts CB, et al. Prevalence of visual impairment in the adult Japanese population by cause and severity and future projections. Ophthalmic Epidemiol. 2010;17(1):50-57.

3. Webers CA, Beckers HJ, Nuijts RM, Schouten JS. Pharmacological management of primary open-angle glaucoma: second-line options and beyond. Drugs Aging. 2008;25(9):729-759.

4. Gestel AV, Webers CA, Beckers HJ, Peeters A, Severens JL, Schouten JS. Ocular hypertension and the risk of blindness. J Glaucoma. March 20, 2013. [Epub ahead of print.]

5. Epstein DL, Grant WM. Carbonic anhydrase inhibitor side effects. Serum chemical analysis. Arch Ophthalmol. 1977;95(8):1378-1382.

6. Koella WP. CNS-related (side-)effects of beta-blockers with special reference to mechanisms of action. Eur J Clin Pharmacol. 1985;Suppl 28: 55-63. 
7. Kass MA, Heuer DK, Higginbotham EJ, et al. The Ocular Hypertension Treatment Study: a randomized trial determines that topical ocular hypotensive medication delays or prevents the onset of primary openangle glaucoma. Arch Ophthalmol. 2002;120(6):701-713.

8. Cheng JW, Cheng SW, Gao LD, Lu GC, Wei RL. Intraocular pressure-lowering effects of commonly used fixed-combination drugs with timolol: a systematic review and meta-analysis. PLoS One. 2012;7(9):e45079.

9. Martinez A, Sanchez-Salorio M. A comparison of the long-term effects of dorzolamide $2 \%$ and brinzolamide $1 \%$, each added to timolol $0.5 \%$, on retrobulbar hemodynamics and intraocular pressure in open-angle glaucoma patients. J Ocul Pharmacol Ther. 2009;25(3): 239-248.

10. Michaud JE, Friren B; International Brinzolamide Adjunctive Study Group. Comparison of topical brinzolamide 1\% and dorzolamide $2 \%$ eye drops given twice daily in addition to timolol $0.5 \%$ in patients with primary open-angle glaucoma or ocular hypertension. Am JOphthalmol. 2001;132(2):235-243.

11. Shin D. Adjunctive therapy with brinzolamide $1 \%$ ophthalmic suspension (Azopt) in patients with open-angle glaucoma or ocular hypertension maintained on timolol therapy. Surv Ophthalmol. 2000; 44 Suppl 2:S163-S168.

12. March WF, Ochsner KI. The long-term safety and efficacy of brinzolamide $1.0 \%$ (Azopt) in patients with primary open-angle glaucoma or ocular hypertension. The Brinzolamide Long-Term Therapy Study Group. Am J Ophthalmol. 2000;129(2):136-143.

13. Schenker H, Maloney S, Liss C, Gormley G, Hartenbaum D. Patient preference, efficacy, and compliance with timolol maleate ophthalmic gel-forming solution versus timolol maleate ophthalmic solution in patients with ocular hypertension or open-angle glaucoma. Clin Ther. 1999;21(1):138-147.

14. Shedden A, Laurence J, Tipping R; Timoptic-XE 0.5\% Study Group. Efficacy and tolerability of timolol maleate ophthalmic gel-forming solution versus timolol ophthalmic solution in adults with openangle glaucoma or ocular hypertension: a six-month, double-masked, multicenter study. Clin Ther. 2001;23(3):440-450.

15. Chrai SS, Makoid MC, Eriksen SP, Robinson JR. Drop size and initial dosing frequency problems of topically applied ophthalmic drugs. J Pharm Sci. 1974;63(3):333-338.

16. Djafari F, Lesk MR, Harasymowycz PJ, Desjardins D, Lachaine J. Determinants of adherence to glaucoma medical therapy in a long-term patient population. J Glaucoma. 2009;18(3):238-243.

17. Sleath B, Robin AL, Covert D, Byrd JE, Tudor G, Svarstad B. Patientreported behavior and problems in using glaucoma medications. Ophthalmology. 2006;113(3):431-436.

18. Auger GA, Raynor M, Longstaff S. Patient perspectives when switching from Cosopt ${ }^{\circledR}$ (dorzolamide-timolol) to Azarga (brinzolamide-timolol) for glaucoma requiring multiple drug therapy. Clin Ophthalmol. 2012;6: 2059-2062.

19. Lanzl I, Raber T. Efficacy and tolerability of the fixed combination of brinzolamide $1 \%$ and timolol $0.5 \%$ in daily practice. Clin Ophthalmol. 2011;5:291-298

20. Manni G, Denis P, Chew P, et al. The safety and efficacy of brinzolamide $1 \% /$ timolol $0.5 \%$ fixed combination versus dorzolamide $2 \% /$ timolol $0.5 \%$ in patients with open-angle glaucoma or ocular hypertension. J Glaucoma. 2009;18(4):293-300.

21. Mundorf TK, Rauchman SH, Williams RD, Notivol R; Brinzolamide/ Timolol Preference Study Group. A patient preference comparison of Azarga (brinzolamide/timolol fixed combination) vs Cosopt (dorzolamide/timolol fixed combination) in patients with openangle glaucoma or ocular hypertension. Clin Ophthalmol. 2008;2(3): $623-628$
22. Kaback M, Scoper SV, Arzeno G, et al; Brinzolamide 1\%/Timolol 0.5\% Study Group. Intraocular pressure-lowering efficacy of brinzolamide $1 \%$ /timolol $0.5 \%$ fixed combination compared with brinzolamide $1 \%$ and timolol 0.5\%. Ophthalmology. 2008;115(10):1728-1734.

23. Greve EL. Performance of computer assisted perimeters. Doc Ophthalmol. 1982;53(4):343-380.

24. McCarty CA, Mukesh BN, Kitchner TE, et al. Intraocular pressure response to medication in a clinical setting: the Marshfield Clinic Personalized Medicine Research Project. J Glaucoma. 2008;17(5): 372-377.

25. Kashiwagi K. Changes in trend of newly prescribed anti-glaucoma medications in recent nine years in a Japanese local community. Open Ophthalmol J. 2010;4:7-11.

26. Brandt JD, Cantor LB, Katz LJ, Batoosingh AL, Chou C, Bossowska I; Ganfort Investigators Group II. Bimatoprost/timolol fixed combination: a 3-month double-masked, randomized parallel comparison to its individual components in patients with glaucoma or ocular hypertension. J Glaucoma. 2008;17(3):211-216.

27. Higginbotham EJ, Olander KW, Kim EE, Grunden JW, Kwok KK, Tressler CS; United States Fixed-Combination Study Group. Fixed combination of latanoprost and timolol vs individual components for primary open-angle glaucoma or ocular hypertension: a randomized, double-masked study. Arch Ophthalmol. 2010;128(2):165-172.

28. Sherwood MB, Craven ER, Chou C, et al. Twice-daily $0.2 \%$ brimonidine- $0.5 \%$ timolol fixed-combination therapy vs monotherapy with timolol or brimonidine in patients with glaucoma or ocular hypertension: a 12-month randomized trial. Arch Ophthalmol. 2006;124(9): 1230-1238.

29. Pisella PJ, Pouliquen P, Baudouin C. Prevalence of ocular symptoms and signs with preserved and preservative free glaucoma medication. Br J Ophthalmol. 2002;86(4):418-423.

30. Sall K. The efficacy and safety of brinzolamide $1 \%$ ophthalmic suspension (Azopt) as a primary therapy in patients with open-angle glaucoma or ocular hypertension. Brinzolamide Primary Therapy Study Group. Surv Ophthalmol. 2000;44 Suppl 2:S155-S162.

31. Sanseau A, Sampaolesi J, Suzuki ER Jr, Lopes JF, Borel H. Preference for a fixed combination of brinzolamide/timolol versus dorzolamide/ timolol among patients with open-angle glaucoma or ocular hypertension. Clin Ophthalmol. 2013;7:357-362.

32. Diestelhorst M, Larsson LI; European-Canadian Latanoprost Fixed Combination Study Group. A 12-week, randomized, double-masked, multicenter study of the fixed combination of latanoprost and timolol in the evening versus the individual components. Ophthalmology. 2006;113(1):70-76.

33. Choudhri S, Wand M, Shields MB. A comparison of dorzolamidetimolol combination versus the concomitant drugs. Am J Ophthalmol. 2000;130(6):832-833.

34. Zhao JL, Ge J, Li XX, et al; Xalacom Study Group in China Comparative efficacy and safety of the fixed versus unfixed combination of latanoprost and timolol in Chinese patients with open-angle glaucoma or ocular hypertension. BMC Ophthalmol. 2011;11:23.

35. Inoue K, Shiokawa M, Sugahara M, Wakakura M, Soeda S, Tomita G. Three-month evaluation of dorzolamide hydrochloride/timolol maleate fixed-combination eye drops versus the separate use of both drugs. Jpn J Ophthalmol. 2012;56(6):559-563.

36. Silver LH. Ocular comfort of brinzolamide $1.0 \%$ ophthalmic suspension compared with dorzolamide $2.0 \%$ ophthalmic solution: results from two multicenter comfort studies. Brinzolamide Comfort Study Group. Surv Ophthalmol. 2000;44 Suppl 2:S141-S145.

37. Stein JD, Kim DS, Niziol LM, et al. Differences in rates of glaucoma among Asian Americans and other racial groups, and among various Asian ethnic groups. Ophthalmology. 2011;118(6):1031-1037. 


\section{Publish your work in this journal}

Clinical Ophthalmology is an international, peer-reviewed journal covering all subspecialties within ophthalmology. Key topics include: Optometry; Visual science; Pharmacology and drug therapy in eye diseases; Basic Sciences; Primary and Secondary eye care; Patient Safety and Quality of Care Improvements. This journal is indexed on
PubMed Central and CAS, and is the official journal of The Society of Clinical Ophthalmology (SCO). The manuscript management system is completely online and includes a very quick and fair peer-review system, which is all easy to use. Visit http://www.dovepress.com/ testimonials.php to read real quotes from published authors. 